\title{
A social and spatial analysis of emissions from private vehicle use in Great Britain
}

\author{
T. J. Chatterton \& J. H. Barnes \\ Air Quality Management Resource Centre, \\ University of the West of England, UK
}

\begin{abstract}
This paper will describe a new approach to source apportionment of transport emissions that moves away from traditional approaches which have allocated emissions to point of use, or by journey purpose. Instead, emissions will be attributed spatially to the people responsible for cars that cause the emissions, highlighting how both structural features (such as poor accessibility) or lifestyle choices (such as a preference for large vehicles) impact on air pollution.

In 2010, the UK Department for Transport began making available data from the motor vehicle test (MOT) database. This data provides information on vehicles under 3.5 tonnes, including: make, model, engine size, fuel type and a date and odometer reading for when the test was undertaken. From these last two, it is possible to estimate an annual mileage for nearly every motor vehicle in Great Britain. Using this data it is possible to create both an emissions profile for each individual vehicle, and subsequently an estimate of the total emissions over a year. This data is then linked with a privileged-access dataset from the UK Driver Vehicle Licensing Agency (DVLA) to allow privately owned vehicles to be separated from commercial vehicles, and then to link vehicles to the location of the registered keeper via small area census geographies ( $\sim 700$ households, $\sim 1600$ people).

Using this data, we undertake an analysis of variations in responsibility for motor vehicle emissions both spatially, in terms of geographic spread and level of urbanisation, and socially, through income data and social profiles, created by the UK Office for National Statistics, for each area.

Keywords: air pollution, car use, emissions, spatial analysis, car ownership, exposure.
\end{abstract}




\section{Introduction}

Work on source apportionment of air pollution emissions for motor vehicles has traditionally focussed on point of use for a number of reasons, not least that the predominant concern of air quality management to date, at least in the United Kingdom, has been the reduction of high concentrations of air pollution in discrete 'hotspots'. Not only have attempts to reduce air pollution exceedences by focussing on hotspots largely failed, but links with climate change (Tiwary et al. [1]) as well as increasing concern over regional pollutants such as ozone (Williams [2]) mean that it is increasingly necessary to take action to reduce air pollution through taking a much wider perspective and bringing down overall emissions.

Baldwin et al. [3] have shown that there is potentially much knowledge in terms of emissions management that is worthy of transfer from the domain of air pollution to that of carbon/greenhouse gas management. However, given the increasingly apparent failure of hotspot management to substantially reduce air pollution exceedences, we argue here that there is knowledge and thinking that can be transferred in the other direction, from carbon and energy management to air quality management. In this instance, and with reference to Tiwary et al. [1], we argue that the spatial perspective of air quality management in particular needs to be reconsidered.

\subsection{Who and why, not where and what}

As indicated above, air quality management focusses predominantly on where emissions happen. This is because the main concern, at least with regard to nitrogen oxides and primary particulate matter, has been about managing pollution concentrations. In the UK, where air pollution problems from industry have long since ceased to be a major problem, high pollution concentrations are principally associated with road transport, this being the main reason for over $90 \%$ of UK Air Quality Management Areas having been declared (Faulkner and Russell [4]). In the case of road transport, pollution concentrations tend to be highest closest to the road, the point where emissions occur. However, other than a limited range of traffic management options that arguably often do little other than relocate emissions (and in doing so actually increase overall air pollution and greenhouse gas emissions), there is little that a hotspot approach leads to in the way of possible air pollution reduction strategies. Hence, at least in part, why there are still so many exceedences of limit values for nitrogen dioxide across the UK.

The hotspot approach is overly simplistic in so much as it asks the question "What is causing high concentrations of pollution X in this location?" and comes up with a first order answer of "The vehicles on the roads in close proximity to the exceedences". This then leads to the conclusion that it must be vehicles that are the problem, and therefore applicable solutions will lie either in moving the traffic elsewhere (i.e. traffic management) or reducing the per vehicle emissions by encouraging cleaner vehicles (which, as indicated by the recent vehicle emission 'scandals' has its own problems). What the hotspot approach does not lend itself 
to is tackling the wider issue of why there is so much traffic overall. This is something which requires a much broader analysis than the predominantly technocentric paradigm of air quality management. Rather than simply looking only at the issue of what vehicles are being driven where, in order to reduce emission across the board it will be necessary to give much more consideration to who is driving those vehicles and why and they are making those journeys.

Work elsewhere (Chatterton et al. [5], Marsden et al. [6]) has begun a discussion about how (predominantly carbon) emissions from transport are linked to a range of social activities or 'practices' (Chatterton [7], Reckwitz [8]) such as work, education, leisure, shopping etc. This work argues that the institutions and service providers whose existence presupposes their accessibility by employees and service users, should take a much greater role in managing the externalities that arise from the transport associated with these activities. This work is being developed in a European Horizon 2020 project, CLAiR-City (Citizen Led Air pollution Reduction in Cities www.CLAiR-City.eu) running from 2016-2020 which aims to rewrite how air pollution emissions modelling is done, by putting people and social activities rather than vehicles and facilities at the centre of analysis.

Within this paper, instead of exploring the why of transport emissions, we focus instead on the who. Using an enhanced version of recent publicly released dataset from motor vehicle safety tests (known historically in the UK as the 'MOT' (Ministry of Transport) test) it is possible to attribute emissions from vehicles to the small-area census unit of their 'registered keeper'. Although, for data privacy reasons, it is necessary to aggregate the data for anonymity across these areas (around 700 households, 1600 people) the use of relatively socially homogenous areas designed for interpretation of census data allows reasonably robust analyses to be undertaken with regard to the socio-economic and demographic characteristics of the households within areas who are responsible for driving vehicles and consequently emitting air pollutants.

This dataset will be described briefly below. It is described in greater depth in a number of publications (Chatterton et al. [9], Cairns et al. [10]) as well as being used to explore a range of issues including social justice issues around energy consumption (Chatterton et al. [11, 12]), and financial implications of motor vehicle ownership and use (Chatterton et al. [14,15]). Elsewhere in this volume, a paper uses this data to contrast inequalities between air pollution emissions and exposure (Barnes and Chatterton [16]). Here, however, we will explore how responsibility for emissions from private motor vehicles varies by different socioeconomic, demographic and geographic groups.

\section{Methodology}

\subsection{The 'MOT' dataset}

In 2010, the UK Department for Transport began publishing the records from the annual vehicle roadworthiness inspections (known in the UK as 'MOT' tests). These tests are required for every vehicle over three years old. This data provides 
details of the make and model of each vehicle, engine size, fuel type, date of first registration and colour, along with the recorded mileage at each test. Using the latter, it is possible to estimate the annual mileage of each vehicle (see Wilson et al. [17]). Through analysis of vehicle characteristics (year of registration, engine size, and fuel type) it is possible to generate per $\mathrm{km}$ emissions factors for each vehicle in the test record database. Emissions of $\mathrm{NOx}, \mathrm{PM}_{10}$ and $\mathrm{CO}_{2}$ have been calculated from a set of generic speed based emission factors developed by the Air Quality Management Resource Centre at the University of the West of England (Barnes and Bailey [18]). The emission factors are disaggregated by fuel type, engine size and emission standard compliance (i.e. Euro Standard - this has been assumed from date of first registration). Then, using a national average split of driving applied to each vehicles calculated annual mileage, an estimate is made of the total emissions for each vehicle. A detailed account of this methodology is given in Chatterton et al. [9].

Using additional data on the location of the vehicles' registered keepers provided by the UK Driver and Vehicle Licensing Agency the per-vehicle data is aggregated to second level small-area census units. These are known as Lowerlayer Super Output Areas (LSOAs) (ONS [19]). Through the use of the additional DVLA data, it is possible to identify the locations of the keepers for vehicles less than three years old that do not have test data in the year in question. Then, interpolating between the date of first registration and the first test date, it is possible to estimate the annual mileage for these vehicles. The DVLA data also allows vehicles registered to private keepers to be separated from those registered to companies and or other organisations. Within this study, only private vehicles have been considered.

\subsection{ONS output area classifications}

In order to further explore emissions from these private vehicles, LSOAs were categorised using the Office for National Statistics Output Area Classifications (ONS [20]). These classifications, comprising eight supergroups, 26 groups and 76 subgroups are based on a clustering of 60 different variables from the $2011 \mathrm{UK}$ Census illustrative of the demographic structure, household composition, housing, socio-economic characteristics and employment patterns in each of the 181,408 Census Output Areas (OAs) in England and Wales. For the purposes of this analysis, LSOAs have been classified on the basis of the dominant OA supergroup within each area (by using the modal OA classification in each LSOA - there being an average of around five output areas within an LSOA). The eight supergroups are: Rural Residents, Cosmopolitians, Ethnicity Central, Multicultural metropolitans, Urbanites, Suburbanites, Constrained City Dwellers, and HardPressed Living. These have between two and four groups within them, each with up to four subgroups. Table 1, indicates the groups within each of the eight supergroups. Due to space limitations in this publication, details have not been provided for the 76 subgroups. Pen portraits for each classification are given in ONS [21]. 
Table 1: ONS output area classifications: supergroups and groups with percentage of population.

\begin{tabular}{|c|c|c|c|}
\hline $\begin{array}{c}\text { Rural Residents } \\
\text { (RR) }\end{array}$ & Cosmopolitans (C) & $\begin{array}{l}\text { Ethnicity Central } \\
\text { (EC) }\end{array}$ & $\begin{array}{c}\text { Multicultural } \\
\text { Metropolitans (MM) }\end{array}$ \\
\hline $\begin{array}{c}\text { Farming communities } \\
(3.4 \%)\end{array}$ & $\begin{array}{l}\text { Students around } \\
\text { campus }(1.4 \%)\end{array}$ & $\begin{array}{c}\text { Ethnic family life } \\
(1.9 \%)\end{array}$ & $\begin{array}{l}\text { Rented family living } \\
(6.7 \%)\end{array}$ \\
\hline Rural tenants $(6.7 \%)$ & $\begin{array}{c}\text { Inner-city students } \\
(0.6 \%) \\
\end{array}$ & $\begin{array}{c}\text { Endeavouring ethnic } \\
\operatorname{mix}(1.6 \%)\end{array}$ & $\begin{array}{c}\text { Challenged Asian } \\
\text { terraces }(4.4 \%)\end{array}$ \\
\hline \multirow[t]{2}{*}{$\begin{array}{c}\text { Ageing rural dwellers } \\
(1.1 \%)\end{array}$} & $\begin{array}{c}\text { Comfortable } \\
\text { cosmopolitans }(0.7 \%)\end{array}$ & $\begin{array}{c}\text { Ethnic dynamics } \\
(0.4 \%)\end{array}$ & Asian traits $(4.0 \%)$ \\
\hline & $\begin{array}{c}\text { Aspiring and affluent } \\
(1.7 \%)\end{array}$ & $\begin{array}{c}\text { Aspirational techies } \\
(2.0 \%)\end{array}$ & \\
\hline Urbanites (U) & Suburbanites (S) & $\begin{array}{l}\text { Constrained City } \\
\text { Dwellers (CCD) }\end{array}$ & $\begin{array}{c}\text { Hard-Pressed Living } \\
\text { (HPL) }\end{array}$ \\
\hline $\begin{array}{c}\text { Urban professionals } \\
\text { and families }(10.9 \%)\end{array}$ & $\begin{array}{c}\text { Suburban achievers } \\
(8.5 \%)\end{array}$ & $\begin{array}{c}\text { Challenged diversity } \\
(3.9 \%)\end{array}$ & $\begin{array}{c}\text { Industrious } \\
\text { communities }(4.8 \%)\end{array}$ \\
\hline \multirow[t]{3}{*}{$\begin{array}{c}\text { Ageing urban living } \\
(7.4 \%)\end{array}$} & $\begin{array}{c}\text { Semi-detached } \\
\text { suburbia }(13.3 \%)\end{array}$ & $\begin{array}{l}\text { Constrained flat } \\
\text { dwellers }(0.1 \%)\end{array}$ & $\begin{array}{c}\text { Challenged terraced } \\
\text { workers }(2.6 \%)\end{array}$ \\
\hline & & $\begin{array}{c}\text { White communities } \\
(1.2 \%)\end{array}$ & $\begin{array}{c}\text { Hard-pressed ageing } \\
\text { workers }(4.6 \%)\end{array}$ \\
\hline & & $\begin{array}{c}\text { Ageing city dwellers } \\
(0.5 \%)\end{array}$ & $\begin{array}{c}\text { Migration and churn } \\
(5.5 \%)\end{array}$ \\
\hline
\end{tabular}

\subsection{Air pollution data}

Air pollution data used in this paper come from two sources. $1 \times 1 \mathrm{~km}$ resolution modelled ambient background pollution data were obtained from the UK Department of Environment and Rural Affairs' Modelling of Ambient Air Quality project (Brookes et al. [22]). Point-of-use emissions data were obtained from the UK National Atmospheric Emissions Inventory (NAEI) [23]. The main pollutants that have been considered within this work are nitrogen dioxide $\left(\mathrm{NO}_{2}\right)$ in relation to ambient concentrations and nitrogen oxides $\left(\mathrm{NOx}\right.$ as $\left.\mathrm{NO}_{2}\right)$ for emissions. These have been selected as they have the strongest relationship with road transport. It should be noted that not only is $\mathrm{NO}_{2}$ generally found to be a good proxy for ultrafine particles (Arain et al. [24], Pekkanen and Kulmala [25]) but local emissions of NOx (particularly from road transport) can be considered as a proxy for much wider health and environmental impacts of motor vehicles (such as noise, vibration, poor quality public space, urban stress etc.).

\section{Results}

\subsection{Spatial variations in concentrations and emissions}

Figure 1 shows maps comparing ambient $\mathrm{NO}_{2}$ concentrations for LSOAs, pointof-use emissions from road transport and emissions of NOx from private vehicles registered in each area (from the MOT dataset). To be completely clear, the emissions depicted in the right-hand map do not occur within the areas; they may be emitted anywhere. This map shows the emissions attributed to the location of the registered keeper - the person best held to be responsible for those emissions, 
in a similar way to how they would, without evidence to the contrary, be responsible with regard to speeding, parking or other motoring offences).

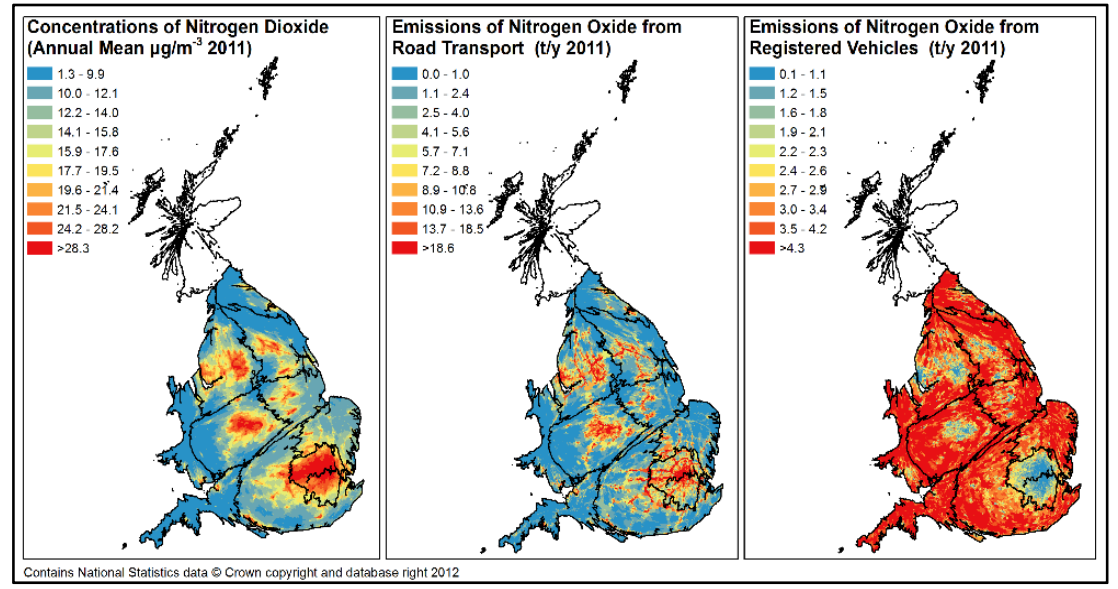

Figure 1: Cartograms (areas based on population) showing background concentrations of $\mathrm{NO}_{2}$, point-of-use emissions of $\mathrm{NOx}$ from road transport and emissions from vehicles registered in each LSOA. Black lines indicate boundaries of the UK regions and Devolved Administrations to aid orientation.

The data in Figure 1 have been presented using cartograms (Tobler [26], Gastner and Newman [27]) in order to better visualise the data. This is because LSOAs are constructed on the basis of roughly equal populations, and therefore, when mapped normally, rural areas, having a much larger area for a given population, tend to dominate the maps. Using the Cartogram Geoprocessing Tool (Dempsey [28]) in ArcGIS, the LSOA maps were redrawn with areas based on the resident household populations (not including those resident in communal establishments such as prisons, universities etc.). This allows the variation in urban areas to be seen much more clearly. The legend for each of the maps is based on deciles.

The left hand map shows $\mathrm{NO}_{2}$ concentrations, with the red areas showing the highest concentrations predominantly in urban areas and along major transport arteries, whilst rural areas have much lower concentrations and are mainly blue. The centre map shows the conventional emissions map for road transport (on which the modelling for the $\mathrm{NO}_{2}$ concentrations was based). This is very similar to the concentrations map but more clearly highlights urban centres and road networks. On the right is the map drawn using the new 'MOT' dataset. This essentially inverts the other maps, with urban areas, where responsibility for emissions is lowest, appearing blue, and rural areas where responsibility for emissions is greatest appearing red. These maps provide a spatial context to the inequalities between emissions and exposure described and discussed in Barnes and Chatterton [16]. 


\subsection{Social variations in concentrations and emissions}

Figure 1 indicates that there are very significant spatial differences in patterns of exposure and responsibility for emissions. In order to move from a very physical account of why these differences occur (e.g. density of emission sources, scarcity of public transport facilities etc.) we return to the theme of the paper discussed earlier: who is responsible for the emissions or is being exposed to higher concentrations of pollution?

In order to answer this, the ONS Output Area Classifications, described above in section 2.2, have been used to categorise the LSOAs, allowing variations to be better understood in terms of both the physical characteristics of an area (not just level of urbanisation, but also factors such as housing type) as well as sociodemographic characteristics (such as age, ethnicity, employment etc.). The following plots show each of the 76 OAC subgroups, however these have been grouped by supergroup (indicated by colour and bracketed letters in the legends) and by group (indicated by colour and point shape, and listed in the legends).

Figure 2 shows the relationship between exposure to concentrations and responsibility for emissions for each of the subgroups. The strong inverse relationship suggested by the maps in Figure 1 is very clear, with an overall correlation coefficient (Pearson's R) of - 0.81 . The 'Rural Resident' supergroup clearly stands out as the areas with the greatest emissions and lowest concentrations. At the other end of the scale, the 'Cosmopolitan' and 'Ethnicity Central' areas tend to be exposed to the highest concentrations whilst being



Figure 2: Comparison of NOx emissions from vehicles registered to residents, against $\mathrm{NO}_{2}$ concentrations per LSOA, by dominant OAC group (shape) and supergroup (colour). $\mathrm{R}=-0.81$. 
responsible for the lowest emissions. To provide a flavour of these, pen portraits for two of these supergroups have been reproduced in Table 2 (from ONS [21]. As evident from the plots though, within each supergroup the subgroups indicate a diversity of pollution exposure/emissions and also likely social characteristics. It is interesting to note how the different subgroups for each supergroup tend to be well clustered.

Table 2: 'Pen Portraits' for highest and lowest emitting/exposed supergroups.

\begin{abstract}
Rural Residents: The population of this supergroup live in rural areas that are far less densely populated compared with elsewhere in the country. They will tend to live in large detached properties which they own and work in the agriculture, forestry and fishing industries. The level of unemployment in these areas is below the national average. Each household is likely to have multiple motor vehicles, and these will be the preferred method of transport to their places of work. The population tends to be older, married and well educated. An above average proportion of the population in these areas provide unpaid care and an above average number of people live in communal establishments (most likely to be retirement homes). There is less ethnic integration in these areas and households tend to speak English or Welsh as their main language.
\end{abstract}

Cosmopolitans: The majority of the population in this supergroup live in densely populated urban areas. They are more likely to live in flats and communal establishments, and private renting is more prevalent than nationally. The group has a high ethnic integration, with an above average number of residents from EU accession countries coinciding with a below average proportion of persons stating their country of birth as the UK or Ireland. A result of this is that households are less likely to speak English or Welsh as their main language. The population of the group is characterised by young adults, with a higher proportion of single adults and households without children than nationally. There are also higher proportions of full-time students. Workers are more likely to be employed in the accommodation, information and communication, and financial related industries, and using public transport, or walking or cycling to get to work.

From ONS [21].

\title{
3.3 Patterns of car ownership and use
}

Having established that there are strong variations in emissions from private car use between different areas, using further data from the 'MOT' data set and the 2011 UK Census it is possible to explore in greater depth how these arise. Firstly, data from the Census allows patterns of ownership for each of the LSOA OAC groupings to be analysed. Figure 3 plots the percentage of households with access/no access to a car or van, against the average number of cars/vans that those households with cars have access to. Again there is a very strong negative correlation $(\mathrm{R}=-0.86)$. This indicates that in those types of areas that have access to vehicles, those households with vehicles tend to have access to a greater number of them.

Whilst there is a strong relationship between type of areas and car ownership/access, it is not just access to a car that determines emissions but how 'clean' the car is (in terms of emissions per $\mathrm{km}$ ) and how far it is driven. Using the data from the 'MOT' dataset that have been used to calculate the emissions in the right hand plot of Figure 1 and the $\mathrm{x}$-axis of Figure 2, the average distance driven and the average distance driven by vehicles in each LSOA have been plotted in Figure 3, again using the OAC classifications. Again, we see a very similar clustering of the supergroups, and a strong correlation between the 


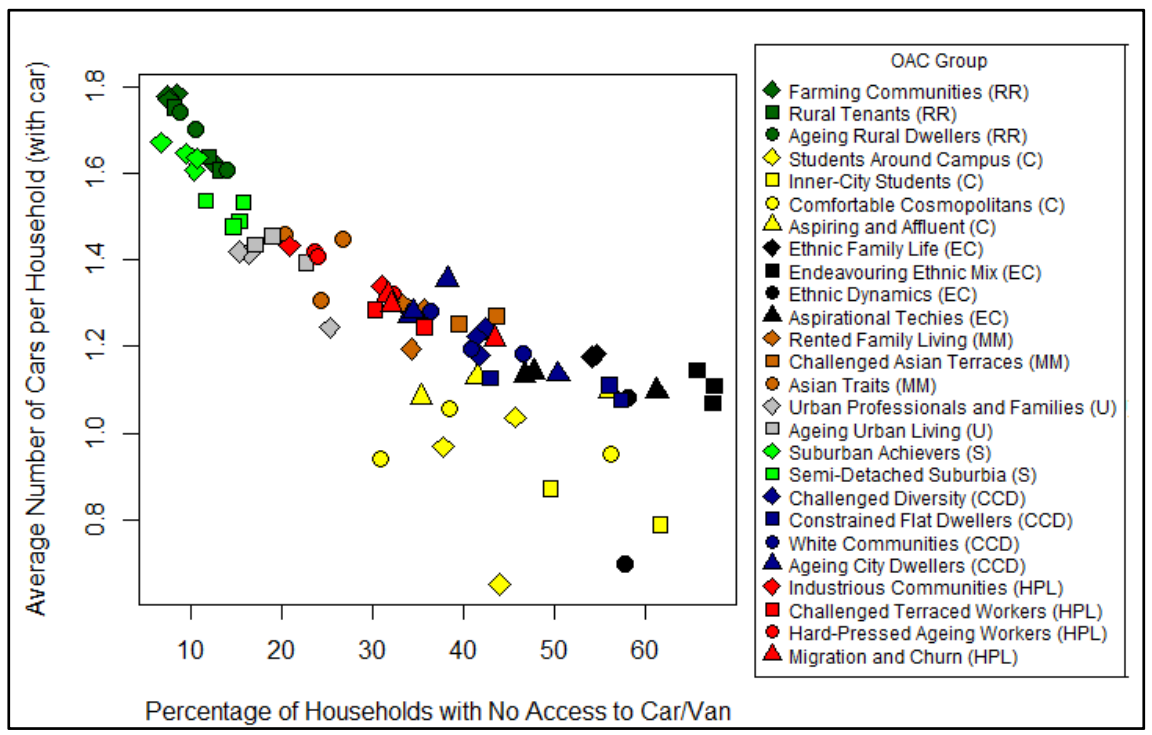

Figure 3: Car ownership per LSOA, by dominant OAC group (shape) and supergroup (colour). $\mathrm{R}=-0.86$.

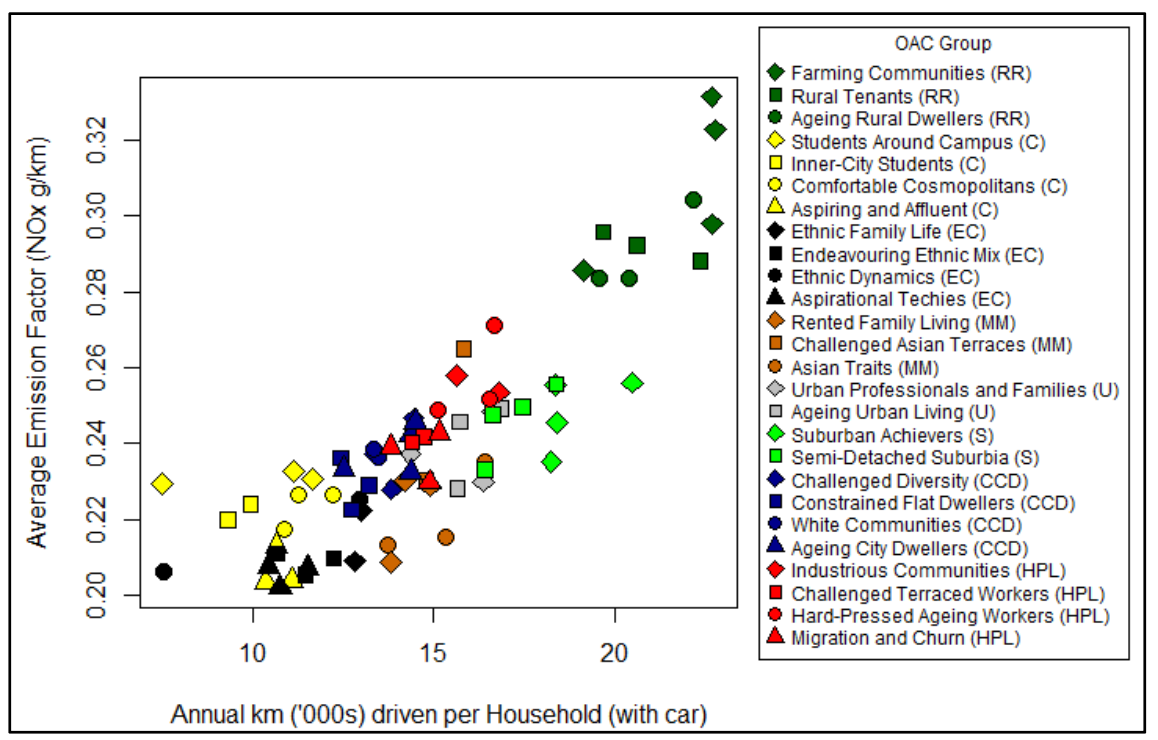

Figure 4: Comparison of average NOx emission factors for vehicles registered to residents, against average distance driven by households with cars, by dominant OAC group (shape) and supergroup (colour). $\mathrm{R}=0.87$. 
variables $(\mathrm{R}=0.87)$. This indicates that in areas where greater distances are driven, cars are likely to emit more NOx. This is likely to be associated with the fact that, as identified in other work (Chatterton et al. [9]) these (mainly rural) areas are likely to have a greater proportion of diesel vehicles due to their greater fuel efficiency. Conversely, in urban areas, the notion of a small, petrol-engined 'city car' appears likely to have a basis in reality.

\section{Conclusions}

This paper has outlined how, by using new datasets about vehicle ownership and usage, it is possible to develop a completely new perspective on air pollution, particularly with regard to emissions. Rather than taking a traditional view of source apportionment, that attributes emissions to types of vehicles and points-ofuse, we have set out an analysis based around the people who own the vehicles and the places they live. This opens up a new realm of possibility for developing strategies to reduce air pollution: ones that can move away from the failed approaches of hotspot management and instead recognise that exceedences of limit values on the current scale indicate that air pollution is not a problem of isolated hotspots, but instead an engrained problem woven into the physical, spatial and social structures of the way we live.

\section{Acknowledgements}

The work has been undertaken under EPSRC Grant EP/K000438/1. Grateful thanks to members of DfT, VOSA, DVLA and DECC, who have provided advice and support for this work. We would particularly like to acknowledge other members of the MOT project team: Prof. Jillian Anable, Dr Sally Cairns, Prof. Eddie Wilson, Dr Oliver Turnbull, Simon Ball and Paul Emmerson for their contributions to the work presented here.

Contains National Statistics and Ordnance Survey data (C) Crown copyright and database right 2012.

MOT Project website www.MOTproject.net

\section{References}

[1] Tiwary, A., Chatterton, T. and Namdeo, A., Co-managing carbon and air quality: pros and cons of local sustainability initiatives. Journal of Environmental Planning and Management, 57(8), pp. 1266-1283, 2014.

[2] Williams, M.L., 2007. UK air quality in 2050 - synergies with climate change policies. Environmental Science \& Policy, 10(2), pp. 169-175.

[3] Baldwin, S.T., Everard, M., Hayes, E.T., Longhurst, J.W.S. and Merefield, J.R., Exploring barriers to and opportunities for the co-management of air quality and carbon in South West England: a review of progress. Air pollution, 17, pp. 101-10, 2009. 
[4] Faulkner, M., and Russell P. Review of Local Air Quality Management: A Report to Defra and the Devolved Administrations, January 2010.

[5] Chatterton, T., Williams, D., Marsden, G., Mullen, C., Anable, J., Docherty, I., Faulconbridge, J., Cass, N., Roby, H. and Doughty, K. Flexi-mobility: Helping local authorities unlock low carbon travel? University Transport Studies Group (UTSG) 47th Annual Conference, London, 5-7 January 2015.

[6] Marsden, G., Anable, J., Chatterton, T., Docherty, I., Faulconbridge, J., Mullen, C., Murray, L. and Roby, H. Fleximobility: Unlocking Low Carbon Travel, Project Brochure, 2015.

[7] Chatterton, T., An introduction to thinking about 'energy behaviour': A multi-model approach. Department of Energy and Climate Change, 2011.

[8] Reckwitz, A., Toward a theory of social practices: a development in culturalist theorizing. European journal of social theory, 5-2, 243-263, 2002.

[9] Chatterton, T., Barnes, J., Wilson, R.E., Anable, J., and Cairns, S., Use of a novel dataset to explore spatial and social variations in car type, size, usage and emissions, Transportation Research Part D, 39, 151-164, 2015.

[10] Cairns, S., Wilson, R.E., Chatterton, T., Anable, J., Notley, S. and McLeod, F., Using MOT test data to analyse travel behaviour change - scoping report. TRL PPR578, Wokingham, 2013.

[11] Chatterton, T., Barnes, J., Yeboah, G. and Anable, J., Energy Justice? A spatial analysis of variations in household direct energy consumption in the UK, Proceedings of the ECEEE Summer Study, France, June 2015

[12] Chatterton, T., Anable, J. Barnes, J. and Yeboah, G. (In Press), Mapping household direct energy consumption in the United Kingdom to provide a new perspective on energy justice, Journal of Energy Research and Social Science, 2016.

[14] Chatterton, T., Anable, J., Cairns, S., Wilson, R. E. and Yeboah, G., Financial implications of car ownership and use. University Transport Studies Group 48th Annual Conference, Bristol, UK, 6-8 January 2016.

[15] Chatterton, T., Anable, J., Cairns, S. and Wilson, R., Financial implications of car use and the drive to work: A social and spatial distributional analysis using income data and area classifications. DEMAND Conference 2016, Lancaster, UK, 13-15 April 2016.

[16] Barnes, J.H. and Chatterton, T., An environmental justice analysis of exposure to traffic-related pollutants in England and Wales Air Pollution $X X V I$, Proceedings of the 24th International Conference on Modelling, Monitoring and Management of Air Pollution, Greece, 20-22 June 2016.

[17] Wilson, R.E., Anable, J., Cairns, S., Chatterton, T., Notley, S. and LeesMiller, J.D., On the estimation of temporal mileage rates. Transportation Research Part E, Volume 60, December 2013, pp. 126-139, 2013.

[18] Barnes, J., and Bailey, R. Quantitative and Qualitative Assessment of the South Yorkshire ECO Stars Fleet Recognition Scheme, Report by Air Quality Management Resource Centre, University of the West of England, Bristol for Barnsley Metropolitan Council, October 2013. 
[19] ONS, The Census Geographies - A beginners guide to UK geography, UK Office for National Statistics, 2016

[20] ONS, 2011 Area Classifications, UK Office for National Statistics, London, April 2015.

[21] ONS, Pen Portraits for the 2011 Area Classification for Output Areas, UK Office for National Statistics, London, April 2015.

[22] Brookes, D.M., Stedman, J.R., Kent, A.J., King, R.J., Venfield, H.L., Cooke, S.L., Lingard, J.J.N., Vincent, K.J., Bush, T.J. and Abbott, J., Technical report on UK supplementary assessment under the Air Quality Directive (2008/50/EC), the Air Quality Framework Directive (96/62/EC) and Fourth Daughter Directive (2004/107/EC) for 2011. Report for the Defra and the UK Devolved Administrations, 2013.

[23] NAEI, Emission Maps for the UK and Devolved Administrations, National Atmospheric Emissions Inventory, 2016.

[24] Arain, M.A., Blair, R., Finkelstein, N., Brook, J. and Jerrett, M., Meteorological influences on the spatial and temporal variability of $\mathrm{NO}_{2}$ in Toronto and Hamilton. The Canadian Geographer/Le Géographe canadien, 53 (2), pp. 165-190, 2009.

[25] Pekkanen, J. and Kulmala, M., Exposure assessment of ultrafine particles in epidemiologic time-series studies. Scandinavian journal of work, environment and health, pp. 9-18, 2004.

[26] Tobler, W. Thirty Five Years of Computer Cartograms, Annals of the Association of American Geographers, 94:1, 58-73, 2004.

[27] Gastner, M.T. and Newman, M.E.J., Diffusion-based method for producing density-equalizing maps. Proceedings of the National Academy of Science, 101(20), 7499-7504, 2004.

[28] Dempsey C. (2012) How To Make Area Cartogram Maps in ArcGIS, GIS Lounge Website: Maps and Cartography, 2013. 